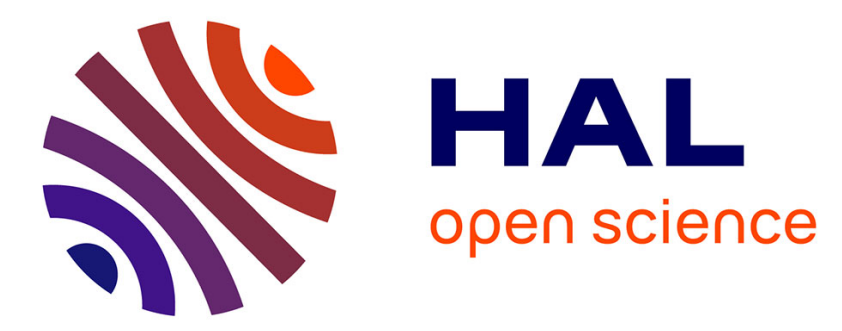

\title{
Performance-based design and carbonation of concrete with high fly ash content
}

\author{
A. Younsi, Ph Turcry, E. Rozière, Abdelkarim Aît-Mokhtar, A. Loukili
}

\section{To cite this version:}

A. Younsi, Ph Turcry, E. Rozière, Abdelkarim Aît-Mokhtar, A. Loukili. Performance-based design and carbonation of concrete with high fly ash content. Cement and Concrete Composites, 2011, 33 (10), pp.993 - 1000. 10.1016/j.cemconcomp.2011.07.005 . hal-01007180

\section{HAL Id: hal-01007180 \\ https://hal.science/hal-01007180}

Submitted on 17 Jan 2017

HAL is a multi-disciplinary open access archive for the deposit and dissemination of scientific research documents, whether they are published or not. The documents may come from teaching and research institutions in France or abroad, or from public or private research centers.
L'archive ouverte pluridisciplinaire HAL, est destinée au dépôt et à la diffusion de documents scientifiques de niveau recherche, publiés ou non, émanant des établissements d'enseignement et de recherche français ou étrangers, des laboratoires publics ou privés. 


\title{
Performance-based design and carbonation of concrete with high fly ash content
}

\author{
A.Younsi ${ }^{a}$, P. Turcry ${ }^{a}$, E. Rozière ${ }^{b}$, A. Aït-Mokhtar ${ }^{a}$, A. Loukili ${ }^{b}$ \\ a Université de La Rochelle, LEPTIAB, La Rochelle, France \\ ${ }^{\mathrm{b}}$ Institut de Recherche en Génie Civil et Mécanique (GeM), UMR-CNRS 6183, Ecole Centrale de Nantes, Nantes, France
}

\begin{abstract}
This paper reports on an investigation of the durability of high-volume fly ash concrete exposed to car-bonation (XC class in EN 206-1 Standard). The reduction of cement content is assumed to mitigate $\mathrm{CO}_{2}$ emissions due to the production of Portland cement clinker. The durability of concrete is assessed through a performance-based approach. First, a performance-based method was applied to design a con-crete mixture with more than 50\% substitution of cement by fly ash. To cope with the high viscosity of the so-obtained mixture, an air-entraining agent was used. Due to its low cement content, the soobtained mixture does not comply with the prescriptive requirements of the European standard (EN 206-1). Thus, according to the equivalent performance concept, its potential durability has to be proved through com-parison with reference mixtures complying with prescriptive standard requirements. The performance-based evaluation of the durability of the designed mixture and reference mixtures (with Portland cement and blended cement) consisted in porosity and accelerated carbonation tests. The influence of curing mode and thermal treatment duration before carbonation test were also investigated. Whatever the cur-ing mode, the designed mixture was found as resistant to accelerated carbonation as the reference mix-ture containing blended cement.
\end{abstract}

\section{Introduction}

Life cycle assessments reveal that carbon emissions of concrete are mainly due to the production of Portland cement clinker $[1,2]$. For example, the production of cement is responsible for at least $75 \%$ of the carbon emissions of a concrete beam [3]. The production of the main constituent of Portland cement, i.e. clinker, releases from 0.6 to 1 ton of $\mathrm{CO}_{2}$ per ton of product [4]. A solution for reducing carbon emissions of concrete structure is to reduce the clinker content of concrete [5,6]. Habert et al. showed that a $50 \%$ clinker substitution level is enough to meet "factor 2" objectives of the Intergovernmental Panel on Climate Change, i.e. a reduction by half of the $\mathrm{CO}_{2}$ emissions [7]. The use of commercially available blended cements could be a solution but their mean substitution rate of clinker by mineral additions remains rather low. A more efficient solution consists in substituting a significant part of the Portland cement by mineral additions, not during cement production but during concrete production. It is well known that mineral additions, such as fly ash or blast-furnace slag, have binder activity [8].

European standards on concrete actually limit the use of mineral additions as binder. The so-called EN 206-1 Standard on performance, production and conformity of concrete defines several exposure classes [9]. For example, the most current exposure classes, namely "XC" classes, correspond to the reinforced concrete structures exposed to carbonation. For each exposure class, EN 206-1 Standard gives minimum binder content and maximum mineral addition content. This mineral addition content refers to mineral addition added during the mixing of concrete. If blended cements containing the same addition are used, additions are considered as a part of cement content. It is assumed that these specifications result in an appropriate durability.

In alternative to this prescriptive approach of the mix-design, the EN 206-1 Standard allows also a performance-based approach. A concrete mixture may be used even if it does not comply with the prescriptive requirements, provided that equivalent performance with a reference mixture has been proved. The reference mixture has to comply with the EN 206-1 prescriptive requirement for the relevant exposure class. This approach is based on the equivalent performance concept $[10,11]$. The concrete performance can be quantified using general durability indicators (such as porosity or gas permeability) and specific durability tests corresponding to the exposure class. For example, in the case of exposure classes XC, the specific durability test is the accelerated carbonation test [12].

This study is a part of a research program on low $\mathrm{CO}_{2}$ emissions concrete. Its objective is to investigate the feasibility of such a concrete designed within the scope of performance-based approach. A mix-design method of concrete with high substitution of cement 
by mineral addition is presented. The method is based on the optimisation of the water-binder ratio with respect to early age strength [13]. The contribution of mineral addition to strength is classically taken into account with a coefficient of activity [14-17]. In the present study, the method was applied to design mixtures with high substitution of cement by fly ash. The designed mixtures were assumed to be destined for structures only exposed to carbonation (i.e. exposure class XC). The durability of the mixtures was characterised by general and specific durability indicators, namely porosity and accelerated carbonation. The effects of curing mode and oven-drying before accelerated carbonation tests were also studied. Lastly, both performance-based approach and durability indicators concept are discussed through the comparison between the designed mixtures and reference mixtures complying with the prescriptive requirements from the Standard.

\section{Experimental program}

Four concrete mixtures were designed to comply with commonly specified requirements for ready mix concrete, such as slump and workability, early-age strength, 28-day compressive strength. The mixtures contained increasing proportion of fly ash in binder, namely: 0\% (RefI), 30\% (RefII, FA30), and 50\% (FA50). The concrete samples underwent different curing and drying periods then they were exposed to accelerated and natural carbonation. Other properties (porosity, Portlandite content, and water saturation degree) were assessed to understand the influence of the binder composition on the durability of concrete exposed to carbonation.

\subsection{Materials}

The purpose of the experimental study is to apply a performance-based approach of durability to the design of a concrete mixture with $50 \%$ substitution of cement by fly ash (FA50). The performances of FA50 concrete mixture are compared to three reference concrete mixtures. The binder of the first reference mixture Refl is a Portland cement CEM I 52.5N type, the binder of the second mixture RefII is a blended cement CEM II/B-V 32.5 R type (containing $31 \%$ fly ash), and the binder of the third mixture FA30 contains 70\% Portland cement CEM I and 30\% fly ash.

The properties of the cementitious materials are given in Table 1 . Fly ash is low calcium fly ash. The concrete mixtures were prepared with locally available aggregates: a siliceous marine sand $(0 / 4 \mathrm{~mm})$ and two crushed diorite gravels (6/10 and 10/14 mm). A

Table 1

Chemical and physical analysis of cementitious materials.

\begin{tabular}{llll}
\hline & $\begin{array}{l}\text { Portland Cement CEM } \\
\text { I 52.5N }\end{array}$ & $\begin{array}{l}\text { Blended cement CEM II- } \\
\text { BV 32.5 R }\end{array}$ & $\begin{array}{l}\text { Fly } \\
\text { ash }\end{array}$ \\
\hline $\begin{array}{l}\text { Physical properties } \\
\text { Density }\end{array}$ & 3.15 & & \\
$\begin{array}{l}\text { Blaine surface } \\
\left(\mathrm{cm}^{2} / \mathrm{g}\right)\end{array}$ & 3400 & 2.89 & 2.21 \\
$\begin{array}{l}\text { Passing } 45 \mu \mathrm{m} \\
(\%)\end{array}$ & - & 3247 & - \\
Composition (\%) & & & 70 \\
Clinker & 95 & & \\
$\begin{array}{l}\text { Fly ash } \\
\text { Limestone }\end{array}$ & 0 & & \\
$\mathrm{Chemical} \mathrm{composition} \mathrm{( \% )}_{\mathrm{CaO}}$ & 0 & 69 & 0 \\
$\mathrm{SiO}_{2}$ & 64.8 & 22 & 100 \\
$\mathrm{Al}_{2} \mathrm{O}_{3}$ & 20.5 & 4 & 0 \\
$\mathrm{Fe}_{2} \mathrm{O}_{3}$ & 4.5 & 49.0 & \\
$\mathrm{SO}_{3}$ & 2.7 & 27.4 & 5.2 \\
\hline
\end{tabular}

polycarboxylate type superplasticizer and an air-entraining agent were used to improve the workability.

\subsection{Experimental procedures}

\subsubsection{Curing and preconditioning of concrete samples}

The influence of curing on the durability indicators was investigated. Two conservation modes before the age of 28 days were compared. After demoulding at $24 \mathrm{~h}$, a first set of $11 \times 22 \mathrm{~cm}$ cylinders was stored in a room at $20^{\circ} \mathrm{C}$ and $\mathrm{RH}$ between $50 \%$ and $70 \%$. A second set of cylinders was cured under water. In the following sections, these two conservation modes are referred as "air-curing" and "water-curing", respectively.

\subsubsection{Assessment of general durability indicators}

Water porosity was measured on three discs $11 \mathrm{~cm}$ in diameter and $5 \mathrm{~cm}$ thick, obtained from sawing of $11 \times 22 \mathrm{~cm}$ cylinders. According to the AFPC-AFREM procedure, porosity was assessed from water saturation under vacuum [18].

The compressive strength was measured on cylindrical specimens, $11 \mathrm{~cm}$ in diameter and $22 \mathrm{~cm}$ in height, at the ages of 2, 7 and 28 days. The specimens were conserved in water before the compressive test.

In order to assess Portlandite $(\mathrm{CH})$ contents in the case of an air-curing mode, TGA (thermo-gravimetric analysis) tests were performed on pastes with the proportions $\mathrm{W} / \mathrm{C}, \mathrm{FA} / \mathrm{C}$ (chemical admixtures/cement mass ratios) used in the concrete mixtures. At the age of $24 \mathrm{~h}$, the pastes were broken in small pieces (of about $100 \mathrm{mg}$ ) and then conserved in a cell at $53.3 \% \mathrm{RH}$, relative humidity imposed by a salt solution of magnesium nitrate. The amounts of $\mathrm{CH}$ were measured at the age of 19 days. TGA was carried out in an Argon atmosphere in order to determine the Portlandite content of cement pastes. The heating rate was $10^{\circ} \mathrm{C} / \mathrm{min}$. The $\mathrm{CH}$ contents expressed in $\mathrm{kg}$ per $\mathrm{m}^{3}$ of concrete were deduced from the $\mathrm{CH}$ content per volume of paste measured by TGA and from the paste fractions of the concrete mixtures.

The water saturation degree of the samples (denoted $S_{1}$ ) after the oven-drying, i.e. just before carbonation test, can be assessed from the following equation:

$S_{\mathrm{l}}=\frac{V_{\mathrm{w}}}{\phi V_{\mathrm{t}}}=\frac{\left(m-\rho_{\mathrm{d}} V_{\mathrm{t}}\right)}{\rho_{\mathrm{w}} \phi V_{\mathrm{t}}}$

with $V_{\mathrm{W}}$ and $V_{\mathrm{t}}$ the volumes of water and sample respectively, $\phi$ the porosity, $m$ the mass of the sample after oven-drying, $\rho_{\mathrm{W}}$ and $\rho_{\mathrm{d}}$ the mass density of water and totally dried concrete respectively. $\rho_{\mathrm{d}}$ was deduced from the porosity measurements.

\subsubsection{Performance-based evaluation of durability}

The potential durability of concrete was assessed through two tests, namely: water porosity and carbonation. Water porosity is a general durability indicator. A more specific durability indicator was investigated, namely the carbonation kinetics. They were assessed by means of accelerated carbonation tests carried out at $20 \pm 2{ }^{\circ} \mathrm{C}$ and $65 \pm 5 \% \mathrm{RH}$ in a chamber filled with $50 \pm 5 \% \mathrm{CO}_{2}$. The relative humidity of $65 \%$ is imposed by a saturated ammonium nitrate solution. At the age of 28 days, $11 \times 22 \mathrm{~cm}$ cylinders were sawn into $10 \mathrm{~cm}$ high cylinders. The sawn sections of the discs were sealed by adhesive aluminium in order to ensure radial $\mathrm{CO}_{2}$ penetration during carbonation tests. The discs were then dried in a ventilated oven at $45^{\circ} \mathrm{C}$. Two durations of this thermal treatment before carbonation test were studied: 2.5 and 14 days. Note that the duration of 14 days is from the French standard procedure XP P18-458 [12]. After the carbonation test, the discs were split and a $\mathrm{pH}$ indicator solution, i.e. phenolphthalein, was sprayed on 
the obtained cross sections in order to determine a carbonation depth after 7, 14, 21, 28, 42 and 120 days.

Another set of $11 \times 22 \mathrm{~cm}$ cylinders was stored, after demoulding at the age of $24 \mathrm{~h}$, in a room at $20^{\circ} \mathrm{C}$ and $\mathrm{RH}$ between $50 \%$ and $70 \%$. These concrete specimens were used to assess carbonation in natural conditions, i.e. with ambient concentration of $\mathrm{CO}_{2}$. Carbonation depths were measured using phenolphthalein spraying on split cylinders at the age of 1 year.

\section{Mix-design of low $\mathrm{CO}_{2}$ emission concrete}

\subsection{Principle of the used mix-design method}

Generally speaking, the mix-design problem consists in determining six unknowns, i.e. $V_{\mathrm{G} 1}, V_{\mathrm{G} 2}, V_{\mathrm{S}}, V_{\mathrm{C}}, V_{\mathrm{FA}}, V_{\mathrm{W}}$, volumes of 2 gravels, sand, cement, fly ash and water, respectively, for a unit concrete volume. The volume of chemical admixtures, such as superplasticizer, is generally neglected. Since the volumetric masses of the constituents are known, the problem can also be expressed in terms of masses, i.e. G1, G2, S, C, FA and W. If the volume fraction of air is assumed to be equal to $2.5 \%$, the following equations are used to solve the problem:

$$
\begin{aligned}
& V_{\mathrm{G} 1}+V_{\mathrm{G} 2}+V_{\mathrm{S}}+V_{\mathrm{C}}+V_{\mathrm{FA}}+V_{\mathrm{W}}=0.975 \mathrm{~m}^{3} \\
& V_{\mathrm{G} 1} / V_{\mathrm{G} 2}=\mathrm{g} \\
& V_{\mathrm{G} 2} / V_{\mathrm{S}}=s \\
& \mathrm{FA} /(\mathrm{FA}+\mathrm{C})=x
\end{aligned}
$$

with $g$ and $s$ the aggregates proportions and $x$ the chosen fly ash/ binder mass ratio.

A fifth equation is given by a relation between the mass composition of the paste (cement, fly ash, water) and the compressive strength. In the case of mixtures with high substitution of cement, the strength at early age may be low. Thus, the composition of paste has to be determined with respect to the early age strength. In the used method, this was done using the Bolomey relation [19], as exposed more in details in [13]:

$f_{\mathrm{c} 2 \mathrm{~d}}=0.5 \sigma\left(\frac{C+k F A}{W}-0.5\right)$

with $f_{\mathrm{c} 2 \mathrm{~d}}$ the 2-day compressive strength, $\sigma$ a coefficient proportional to the cement activity, $k$ the coefficient of activity of fly ash. $\sigma$ and $k$ are determined from compressive tests on mortars. A 2-day strength $\left(f_{\mathrm{c} 2 \mathrm{~d}}\right)$ of at least $10 \mathrm{MPa}$ was assumed to be enough for early age demoulding, i.e. before 1 day. Note that such a criterion on the 2-day strength was preferred to a criterion on strength before 1 day, because the latter is more difficult to measure.

A sixth equation is needed to complete the system. As discussed below, the water content or the paste volume fraction can be fixed.

\subsection{Application to design high cement substitution concrete}

The method was applied to design a mixture with FA/ $(F A+C)=50 \%$, i.e. $x=0.5$ in Eq. (5). It was assumed that the mixture is intended to a reinforced structure exposed to corrosion induced by carbonation. This corresponds to the exposure class denoted XC1 in the EN 206-1 Standard. It should be recalled that the maximum $\mathrm{FA} /(\mathrm{FA}+\mathrm{C})$ ratio allowed by the prescriptive approach of the Standard is equal to $30 \%$ for this exposure XC1 (Table 2).

In Eqs. (3) and (4), the aggregates proportions $g$ and s were chosen equal to those of an existing mixture containing only Portland cement, denoted Refl in Table 3.
Table 2

NF EN 206-1 Standard specifications for the exposure classes XC (maximum gravel diameter $=14 \mathrm{~mm}$ ). The equivalent binder (Eq. binder) content is defined as: $C+k A$ where $k=0.6$ (standardised activity coefficient for fly ash) and $A$ is the mass of fly ash such as $A /(A+C)=30 \%$.

\begin{tabular}{lll}
\hline & XC1 & XC3 \\
\hline Minimum compressive strength $(\mathrm{MPa})$ & 20 & 25 \\
Minimum Eq. binder content $\left(\mathrm{kg} / \mathrm{m}^{3}\right)$ & 280 & 301 \\
Maximum effective Water $-\mathrm{Eq}$. binder ratio & 0.65 & 0.60 \\
Maximum $A /(A+C)(\%)$ & 30 & 30 \\
\hline
\end{tabular}

Table 3

Proportions (in $\mathrm{kg} / \mathrm{m}^{3}$ ) and compressive strengths of the studied mixtures.

\begin{tabular}{llllll}
\hline & Refl & RefII & FA30 & FA50* & FA50 \\
\hline Gravel 10/14 & 875 & 875 & 844 & 846 & 846 \\
Gravel 6/10 & 211 & 211 & 204 & 205 & 205 \\
Sand 0/4 & 855 & 855 & 824 & 827 & 827 \\
CEM I 52.5N & 301 & 0 & 241 & 190 & 190 \\
CEM II-B V 32.5 R & 0 & 321 & 0 & 0 & 0 \\
Fly ash & 0 & 0 & 100 & 190 & 190 \\
Water & 182 & 175 & 182 & 155 & 155 \\
Superplasticizer & 0 & 1.00 & 1.75 & 6.00 & 6.00 \\
AEA & 0 & 0 & 0 & 0 & 0.57 \\
Equivalent binder content C+ kA (kg/ & 301 & 321 & 301 & 239 & 239 \\
$\left.\quad m^{3}\right)$ & & & & & \\
W/(C+ kA) & 0.60 & 0.57 & 0.60 & 0.65 & 0.65 \\
FA/(FA + C) (\%) & 0 & 0 & 30 & 50 & 50 \\
W/C & 0.60 & 0.54 & 0.76 & 0.82 & 0.82 \\
W/(C+ FA) & 0.60 & 0.54 & 0.53 & 0.41 & 0.41 \\
Volume of paste $\left(1 / \mathrm{m}^{3}\right)$ & 280 & 286 & 305 & 302 & 302 \\
Compressive strengths (MPa) & & & & & \\
2 days & 20.0 & 16.4 & 18.0 & 11.0 & 18.0 \\
7 days & 26.0 & - & 26.0 & 20.0 & 26.4 \\
28 days & 35.8 & 31.6 & 33.0 & 28.4 & 31.4 \\
\hline
\end{tabular}

In the Bolomey relation (Eq. (6)), $\sigma$ was taken equal to $24 \mathrm{MPa}$. This value was determined from compressive tests on 2-day old mortars made with the following volume fractions: sand $=5 \%$, water $=30 \%$ and cement $=15 \%$ (i.e. $\mathrm{W} / \mathrm{C}=0.6$ ). The coefficient of activity of the fly ash $(k)$ was also determined from compressive tests on mortars with the same volume fractions of sand, water and powder and with $\mathrm{FA} /(\mathrm{FA}+\mathrm{C})=0.5$. $k$ was obtained equal to 0.1.

To complete the system, the water content could be taken equal to the water content of the existing mixture Refl (i.e. $\left.\mathrm{W}=182 \mathrm{~kg} / \mathrm{m}^{3}\right)$. However, this would result in a high amount of binder $\left(\mathrm{C}+\mathrm{FA}=440 \mathrm{~kg} / \mathrm{m}^{3}\right)$. The coefficient of activity of fly ash is actually very low at early age and, according to the Bolomey relation, a low water on binder ratio is required to obtain the desired strength at 2 days. Secondly, the paste fraction could be taken equal to that of Refl mixture (i.e. $278 \mathrm{l} / \mathrm{m}^{3}$ ). However, this would result in a very low water content $\left(E=144 \mathrm{~kg} / \mathrm{m}^{3}\right)$, which could compromise the concrete compaction. An intermediate solution was chosen: $\mathrm{W}=155 \mathrm{~kg}$.

Finally, the superplasticizer content was adjusted to obtain a slump higher than $150 \mathrm{~mm}$.

Note that more sophisticated approaches to predict strength from the cement and addition contents can be found in literature [14].

Table 3 gives the composition of the mixture obtained by the previous method, denoted FA50*. This mixture appeared to be very viscous at the fresh state. This result points out a natural technical barrier of the proposed mix-design method. The reduction in water content used to guarantee early age strength leads to viscous mixture, although the slump is high.

De Larrard et al. showed that the plastic viscosity of a concrete mixture increases with the relative solid concentration, defined as the ratio between the volume fraction of the solid constituents in 
the mixture and its maximal possible value (i.e. the maximal packing density of the solid skeleton) [14,15]. The main parameter governing the plastic viscosity is thus the water content. However, in order to decrease the viscosity of the FA50* mixture, another solution was proposed: an air-entraining agent (AEA) was added. Air-entraining agents are mainly used to increase the freeze-thaw durability of concrete through the formation of air bubbles dispersed uniformly in the cement paste. But it generally results in increased porosity and thus lower strength. Besides the effect on air content, this type of chemical admixture is known to reduce the viscosity. This side effect can be explained by the resulting decrease in the volume fraction of the solid constituents. The mixture with AEA, denoted FA50, was actually found more workable than FA50*. The proportion of air of FA50 was measured equal to about $5 \%$ by means of an aerometer.

\subsection{Reference concrete mixtures}

Two other mixtures were also designed (Table 3 ). The mixture denoted FA30 was designed in accordance with the standard specifications for the exposure class $\mathrm{XC} 3$, with the maximum cement substitution ratio, i.e. $\mathrm{FA} /(\mathrm{FA}+\mathrm{C})=30 \%$. The mixture denoted RefII has almost the same proportions than Refl but the Portland cement was substituted by a blended cement containing fly ash (CEM II/B-V type cement). Cement content and water content were also a little increased and decreased respectively, in order to obtain a 28-day strength higher than $25 \mathrm{MPa}$.

According to the equivalent performance concept, equivalent performance has to be shown from the comparison with a reference concrete mixture. The reference concrete mixture has to comply with prescriptive requirements but the choice of a reference concrete mixture is debatable. According to guidelines used to apply the equivalent performance concept [20], the reference concrete mixtures have to comply with more restrictive requirements

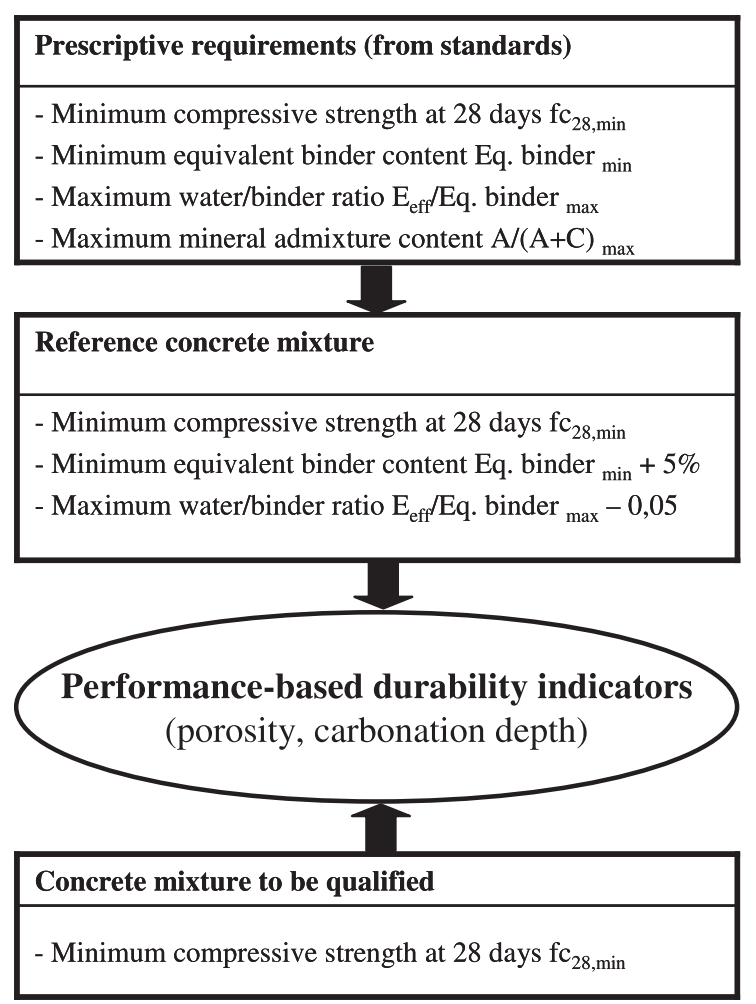

Fig. 1. Application principle of equivalent performance concept in the case of concrete exposed to carbonation [20].
Table 4

Data for estimation of $\mathrm{CO}_{2}$ emissions.

\begin{tabular}{clll}
\hline & $\begin{array}{l}\text { Emissions due to } \\
\text { production phase } \\
\left(\mathrm{kg} \mathrm{CO}_{2} \mathrm{~kg}^{-1}\right)\end{array}$ & $\begin{array}{l}\text { Distances from } \\
\text { factory to ready mix } \\
\text { concrete plant }(\mathrm{km})\end{array}$ & $\begin{array}{l}\text { Emissions due to } \\
\text { transport by road } \\
\left(\mathrm{kg} \mathrm{CO}_{2} \mathrm{t}^{-1} \mathrm{~km}^{-1}\right)\end{array}$ \\
\hline $\begin{array}{l}\text { Aggregates } \\
\text { CEM I 52.5 }\end{array}$ & 0.01 & 200 & 0.08 \\
CEM II & 0.7 & 200 & \\
$\begin{array}{c}\text { 32.5 } \\
\text { Fly ash }\end{array}$ & 0 & 200 & \\
\hline
\end{tabular}

Table 5

$\mathrm{CO}_{2}$ emissions of concrete $\left(\mathrm{kg} / \mathrm{m}^{3}\right)$ due to production (Pr.) and transport (Tr.) of solid raw materials.

\begin{tabular}{|c|c|c|c|c|c|c|c|c|}
\hline & \multicolumn{2}{|l|}{ Refl } & \multicolumn{2}{|c|}{ RefII } & \multicolumn{2}{|c|}{ FA30 } & \multicolumn{2}{|c|}{ FA50 } \\
\hline & Pr. & Tr. & Pr. & Tr. & Pr. & Tr. & Pr. & Tr. \\
\hline Aggregates & 19 & 31 & 19 & 31 & 19 & 30 & 19 & 30 \\
\hline Cement & 211 & 5 & 155 & 4 & 169 & 4 & 133 & 3 \\
\hline Fly ash & 0 & 0 & 0 & 0 & 0 & 8 & 0 & 15 \\
\hline Total & \multicolumn{2}{|c|}{266} & \multicolumn{2}{|c|}{209} & \multicolumn{2}{|c|}{229} & \multicolumn{2}{|c|}{200} \\
\hline
\end{tabular}

than those given by the standard for a given exposure class, i.e. in our case XC1. Principle of equivalent performance concept is schematized in Fig. 1. Refl, RefII and FA30 mixtures comply with the prescriptive requirements for the XC3 exposure class, which are more restrictive than requirement for XC1 class. Thus, they were used as reference mixtures for the XC1 exposure class.

\subsection{Estimation of $\mathrm{CO}_{2}$ emissions}

The substitution of cement by fly ash aims at reducing environmental impacts of concrete, especially $\mathrm{CO}_{2}$ emissions. Thus, the $\mathrm{CO}_{2}$ emissions of the studied mixtures were assessed in order to evaluate the efficiency of the substitution of cement. Table 4 gives the input data. Only the emissions of the production phase, including production and transport of the solid constituents, were calculated. The $\mathrm{CO}_{2}$ emissions due to chemical admixtures were neglected. The fly ash was considered as an industrial waste. Consequently, the production of fly ash does not release greenhouse gases and only the transport of fly ash, from its production site to ready mix concrete factory, was considered. The transport distance of fly ash was deliberately overestimated $(1000 \mathrm{~km})$. The distances of the other constituents are mean values from data of the French ready mix concrete association (SNBPE) [3]. The $\mathrm{CO}_{2}$ emissions of the blended cement (CEM II 32.5) were assessed from its mass fraction of clinker (69\%) and the emissions of the Portland cement $\left(0.7 \mathrm{~kg} \mathrm{CO}_{2} \mathrm{~kg}^{-1}\right)$. The emissions due to fly ash into this cement were neglected, since the cement plant is near the production site of fly ash.

As shown in Table 5, the use of the blended cement is likely to reduce significantly the carbon emission (ReflI mixture). The highest reduction is obtained, when $50 \%$ of cement is substituted by fly ash (FA50 mixture).

\section{Experimental results}

\subsection{Compressive strength}

At the age of 2 days, the compressive strengths of all the tested mixtures are higher than $10 \mathrm{MPa}$ (Table 3). The strength of FA50 mixture is significantly higher than the FA50* mixture, whereas the mix proportions of these two mixtures are almost identical (the same water/binder ratio, especially). 
Firstly, this result may seem paradoxical since the use of an AEA usually results in concrete with higher porosity. However, it can be explained by the lower concrete viscosity due to AEA. In fact, the compaction of a viscous concrete, such as FA50*, is difficult and very likely to be incomplete, although the slump is high. A lack of compaction induces of course a high air content and low strength. The effect of the fresh concrete consistency on compressive strength is not taken into account in most of the mix-design methods. The results of porosity measurements presented hereafter confirm that the FA50 mixture is not more porous than the FA50* mixture, despite of AEA content.

At the age of 28 days, the same tendency can be observed. Except FA50* mixture, all the tested mixtures are equivalent in terms of compressive strength.

\subsection{Porosity}

In Fig. 2, one can notice a systematic influence of curing on porosity: after 28 days under water, all mixtures are 10-20\% less porous than the mixtures stored in air after demoulding. The conservation under water favours the hydration of cement, especially at the external layer of the concrete specimen $[21,22]$.

Due to the addition of AEA, the casting of the FA50 mixture was easier. This mixture is less porous than the FA50* mixture, although these mixtures have the same mix-proportions. This result is consistent with results on compressive strength.

The porosity is governed by several parameters, especially initial porosity (air and initial water content), W/C ratio and degree of cement hydration. Although RefI, RefII, FA30 and FA50 have different compositions, their porosity is roughly similar. Among these four mixtures, the highest porosity is observed for the FA30 mixture with high initial water content $\left(182 \mathrm{~kg} / \mathrm{m}^{3}\right)$ and high $\mathrm{W} / \mathrm{C}$ (0.76). It is worth to note that the FA50 mixture is not the most porous mixture, despite its very high $\mathrm{W} / \mathrm{C}(0.82)$ and high air content due to AEA. The low initial water content of FA50 mixture compensated the effects of those two parameters.

If porosity is taken as a durability indicator of concrete [23], all the tested mixtures, except FA50*, have showed equivalent potential durability, since they have approximately the same porosity, whatever curing conditions.

\subsection{Accelerated carbonation}

\subsubsection{Carbonation of the FA50* mixture}

The resistance against carbonation of the FA50* mixture was found very low. Fig. 3a shows the split sections after the phenolphthalein spray: no clear carbonation front appears. In this figure, it is seen a damaged section with large air voids. This mixture was

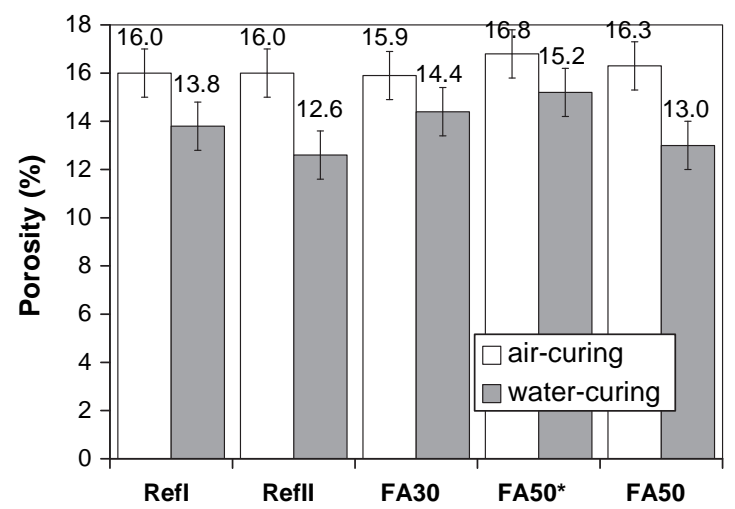

Fig. 2. Porosity.
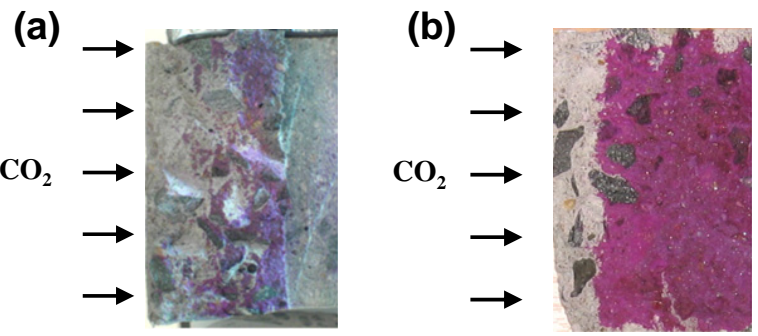

Fig. 3. (a) Split section of a FA50* mixture disc after 7 days in accelerated carbonation chamber. (b) Split section of a Refl mixture disc after 7 days in accelerated carbonation chamber.

actually badly compacted despite vibration. These results confirm that the workability of fresh concrete has a significant influence on long-term behaviour and durability. As a consequence it has to be taken into account in a performance-based design.

In the case of the other mixtures, carbonation depths were measured easily with the $\mathrm{pH}$ indicator (3b).

\subsubsection{Influence of oven-drying before carbonation test}

After 14 days at $45^{\circ} \mathrm{C}$, carbonation is faster than after 2.5 days in the oven (Fig. 4). This illustrates the noticeable effect of drying on the accelerated carbonation kinetics. The diffusion of $\mathrm{CO}_{2}$ is actually $10^{4}$ higher in air than in water. Thus the diffusion of $\mathrm{CO}_{2}$ is affected by the liquid water saturation degree: the drier the porosity, the higher the diffusion [24].

However, the influence of the mix proportions did not depend on the duration of the oven-drying before carbonation test. Indeed, whatever the duration of drying, the FA50 mixture has a higher carbonation kinetic than the FA30 mixture in the case of the aircuring. When the mixtures are stored 28 days under water before tests (water-curing), similar carbonation depths were measured for the two mixtures, also whatever the prior oven-drying duration.

\subsubsection{Influence of curing mode}

The water-curing has a beneficial effect on all the tested mixtures (Fig. 5). The carbonation depths are about $20-50 \%$ lower in the case of water-curing than in the case of air-curing (Fig. 6). Note that the mixtures with the lower clinker contents, i.e. RefII and FA50, are the most influenced by water-curing, as observed on porosity.

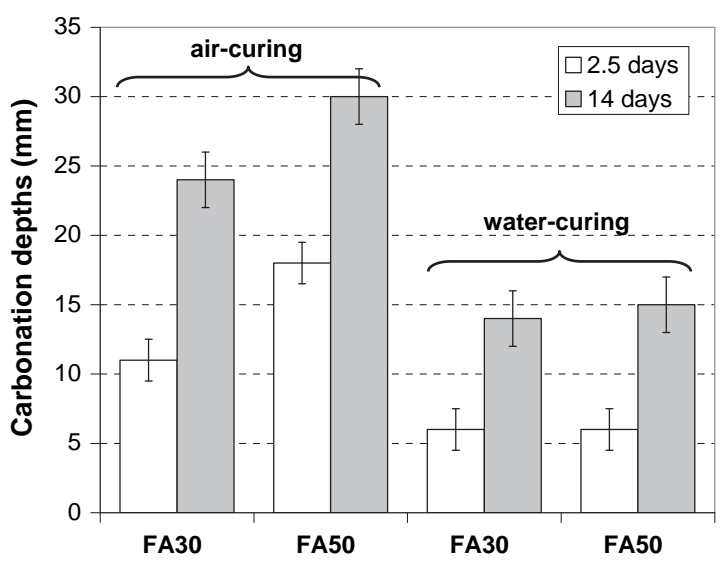

Fig. 4. Influence of oven-drying duration (2.5 or 14 days) on carbonation depths measured after 7 days in carbonation chamber. 

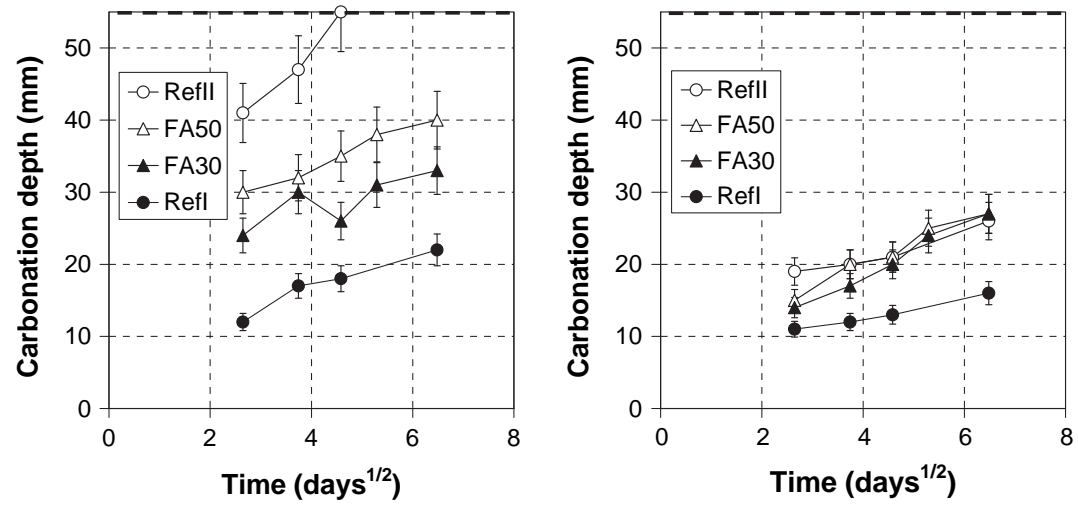

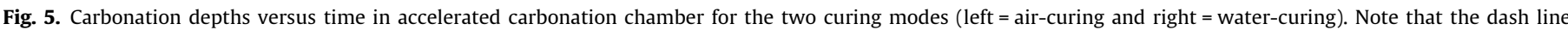
indicates the maximal possible carbonation depth (sample radius $=55 \mathrm{~mm}$ ).

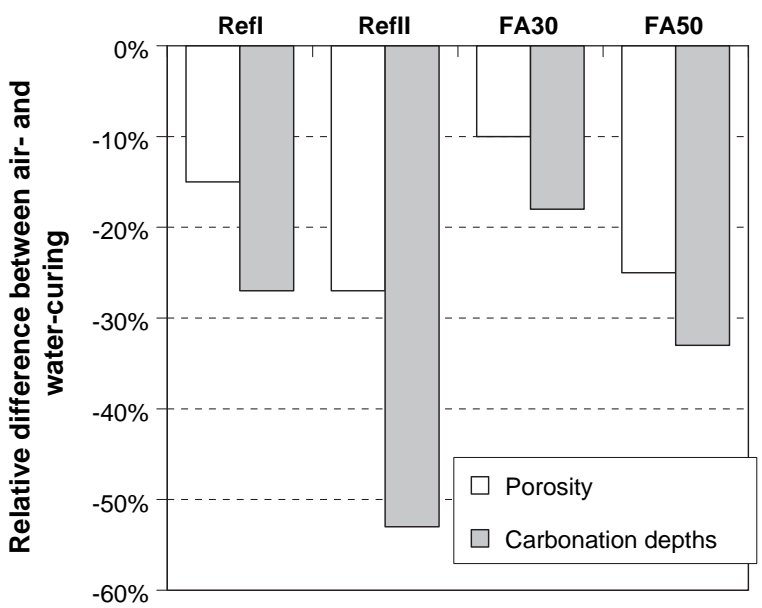

Fig. 6. Relative differences between air- and water-cured mixtures in porosities and 42-day accelerated carbonation depths (oven-drying $=14$ days).

\subsubsection{Influence of composition in the case of air-curing}

Among factors influencing carbonation, two factors are correlated to concrete composition: the total amount of carbonatable constituents and the diffusion coefficient of $\mathrm{CO}_{2}[16,23,24]$.

- The highest carbonation rates of RefII and FA50 mixtures can be explained first by low contents of carbonatable constituents due

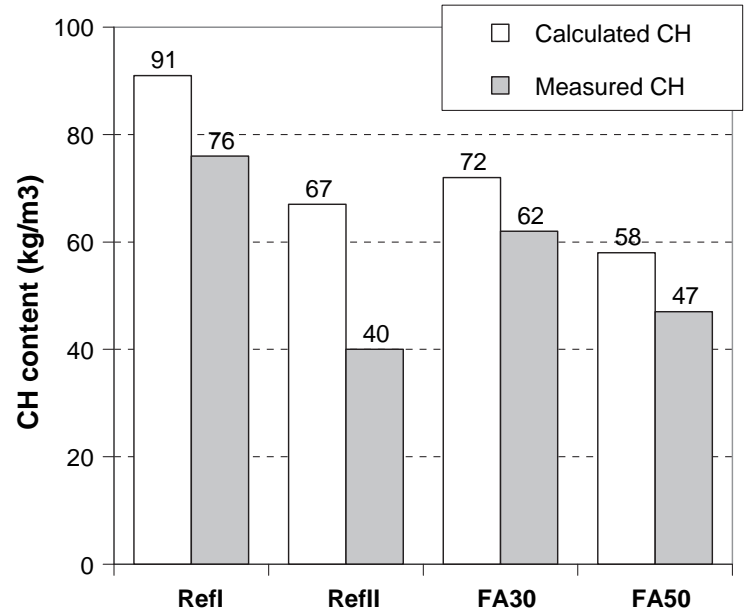

Fig. 7. $\mathrm{CH}$ content $\left(\mathrm{kg} / \mathrm{m}^{3}\right)$. to low clinker content. The content of the main carbonatable constituent, i.e. Portlandite $(\mathrm{CH})$, were assessed from the Bogue Formulas and the chemical reactions of the main cement phases $C_{3} S$ and $C_{2} S[25,26]$. For a complete cement hydration, the calculated $\mathrm{CH}$ content of the FA50 mixture, for example, is about $25 \%$ lower, compared to the FA30 mixture (Fig. 7). Of course, the cement hydration is not complete at the beginning of carbonation tests, since the mixtures were tested before the age of 2 months. Furthermore, the cement hydration at ambient relative humidity is slowed down by drying and consequently the production of carbonatable products is lowered [27]. Moreover, the $\mathrm{CH}$ content is likely to be reduced by the pozzolanic reactions due to fly ash, but this has not been confirmed in experimental studies $[28,29]$. The $\mathrm{CH}$ contents of the RefII and FA50 mixtures are found to be the lowest (Fig. 7). Moreover, the most carbonated mixture, i.e. RefII (completely carbonated after less than 21 days carbonation test), has the lowest $\mathrm{CH}$ content.

- In the case of air-curing, the mixtures porosities are very close. However, the $\mathrm{CO}_{2}$ diffusion coefficient is not only governed by the microstructure but also by its liquid water saturation degree. Fig. 8 illustrates the loss of mass relative to the initial water mass, at $20^{\circ} \mathrm{C}$ and ambient $\mathrm{RH}$ (air-curing) and then at $45^{\circ} \mathrm{C}$ (from 28 days). Carbonation depths are rather well correlated to the losses of mass, since the higher the loss of mass, the faster the carbonation.

The water saturation degree $S_{1}$ was an average water saturation degree, because drying occured from the surface to the core on the

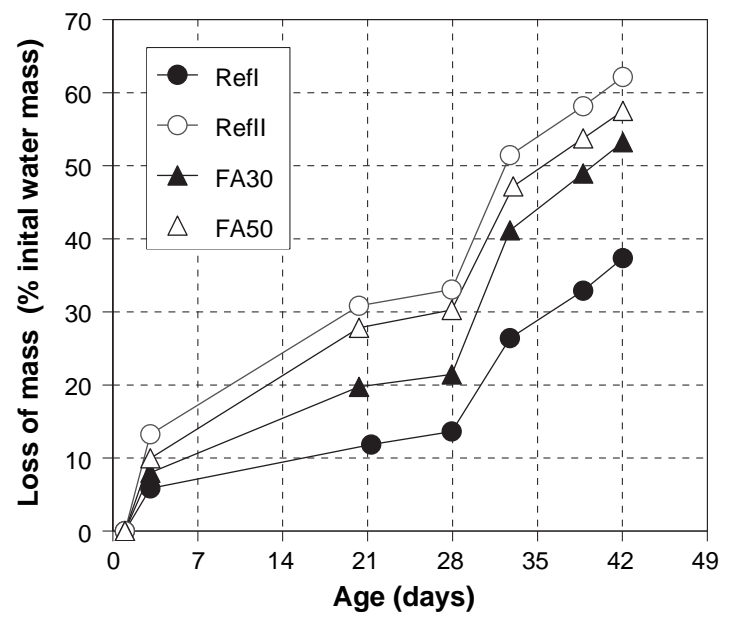

Fig. 8. Loss of mass relative to the initial water mass for "air-cured" mixtures (From 0 to 28 days $=$ drying at $20{ }^{\circ} \mathrm{C}$ and ambient $\mathrm{RH}-$ From 28 to 42 days = oven-drying) 


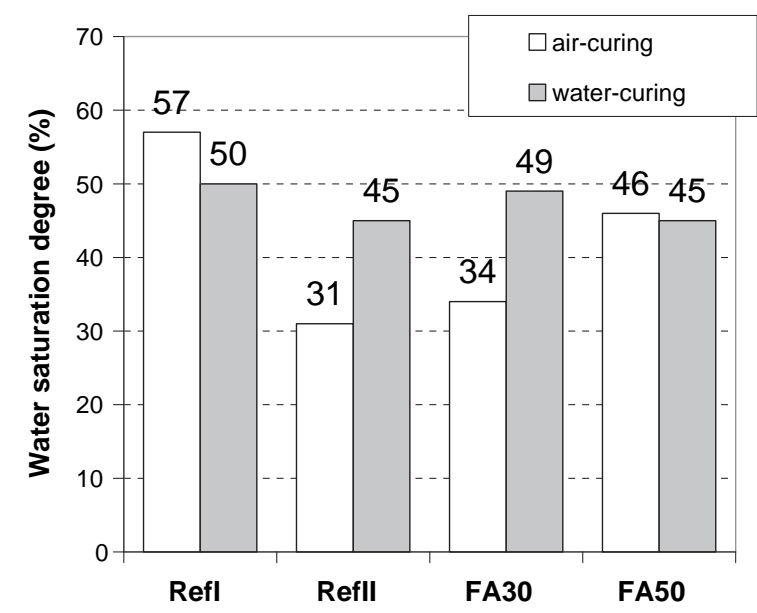

Fig. 9. Average liquid water saturation degree after 14 days oven-drying, just before accelerated carbonation test.

discs. However, these calculated values give interesting tendency (Fig. 9). The RefII mixture was actually found to have the lowest $S_{1}$. Finally, this explains the faster carbonation of RefII mixture, especially when compared to FA50 mixture, which had slightly higher amount of $\mathrm{CH}$ but significantly higher water saturation degree.

\subsubsection{Influence of composition in the case of water-curing}

The Refl mixture has the lowest carbonation depths, as observed in the case of air-curing (Fig. 5). This results mainly from its high $\mathrm{CH}$ content (Fig. 7). Unlike in the case of air-curing, RefII, FA30 and FA50 have however the same carbonation depths, when conserved 28 days under water. It seems that the differences in $\mathrm{CH}$ contents (calculated values given in Fig. 7) are compensated by the differences in porosity. For example, the FA50 mixture has a lower theoretical $\mathrm{CH}$ content but lower porosity, when compared to FA30 mixture. In addition, note that these mixtures have rather similar water saturation degrees (Fig. 9).

\section{Discussions on the evaluation of concrete durability and on the equivalent performance concept}

Porosity measurements and accelerated carbonation tests are frequently used to evaluate concrete durability. These two durability indicators can lead to different conclusions. For example, the FA50 mixture was more carbonated than the Refl mixture, although their porosities are somewhat equal, in both cases of water and air-curing. On the one hand, one can consider that the porosity values are not enough to characterise correctly the durability of concrete with very low clinker content. Porosity gives no information on the content of carbonatable constituents, i.e. one of the main parameters of carbonation resistance. On the other hand, accelerated carbonation tests may be too severe for mixtures with low clinker content. In fact, the drying at $45^{\circ} \mathrm{C}$ before carbonation test dries the first centimetres of the concrete specimens and, thus, makes the diffusion of $\mathrm{CO}_{2}$ inside concrete porosity much faster during the test. Thus, the result of an accelerated carbonation test depends strongly on the content of carbonatable constituents. This makes accelerated test maybe not enough representative of natural carbonation which is also dependent on kinetics of both concrete drying and $\mathrm{CO}_{2}$ diffusion.

Fig. 10 gives natural carbonation depths of cylinders conserved 1 year at $20^{\circ} \mathrm{C}$ and ambient $\mathrm{RH}$, for air-cured and water-cured mixtures. No carbonation could be observed after 1 month in this

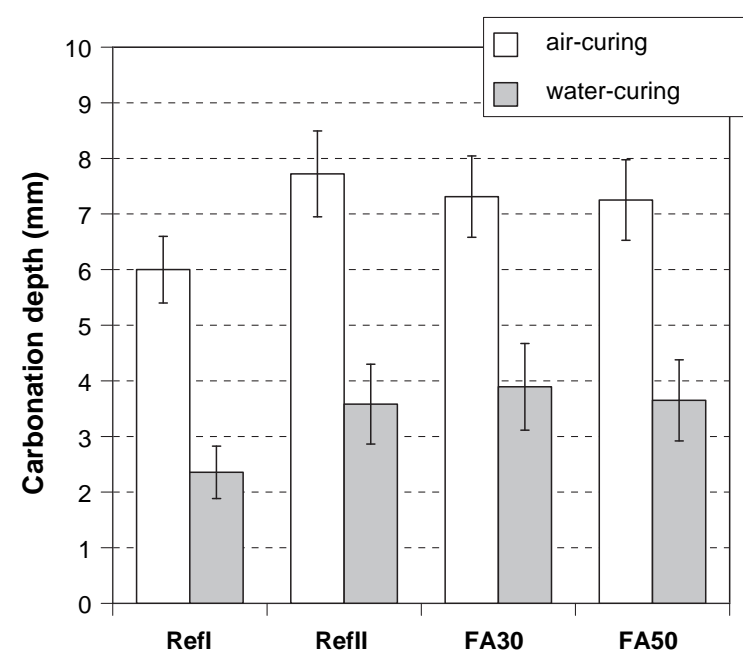

Fig. 10. Natural carbonation depths measured after 1 year in a room at $20^{\circ} \mathrm{C}$ and 50-70\% RH for "air-cured" and "water-cured" mixtures.

ambiance. It is worth noting that, except Refl mixture, the three other mixtures have the same carbonation depth.

In spite of the questionable validity of accelerated carbonation, the FA50 mixture can be said equivalent in terms of performances to the RefII mixture which complies with the prescriptive approach of EN 206-1 Standard. The accelerated carbonation depth was actually found higher for the reference mixture, i.e. ReflI, in the case of air-curing. This curing mode, with a demoulding at the age of $24 \mathrm{~h}$, can be considered as the most representative of the building site. Consequently, the equivalent performance concept can be applied: FA50 mixture can be used in replacement of a concrete mixture complying with the specification of the XC1 exposure class. This mixture was besides tested in a large-scale test, on a construction site of a multi-storey building. It was used in little reinforced partition walls. On construction site, the mixture was easily cast then vibrated and the formworks were removed less than $24 \mathrm{~h}$ after concreting.

\section{Conclusion}

A mix-design method of concrete mixture with a high substitution level of cement by fly ash was developed. The production of such mixtures leads to significantly less $\mathrm{CO}_{2}$ emissions. The potential durability of these mixtures incorporating high proportion of fly ash was assessed through a performance-based approach. According to the equivalent performance concept, its carbonation resistance was compared with several concrete mixtures complying with prescriptive requirements on cement content.

- The used mix-design method made it possible to reach compressive strength at early age higher than $10 \mathrm{MPa}$, through the reduction of the water/binder ratio using the Bolomey relation and experimentally assessed coefficients of activity of fly ash.

- The water-reducing approach is likely to result in a highly viscous mixture and poor compacting ability, and thus lower performances as observed in this study. One solution tested in our study is the use of air-entraining agent (AEA), in order to reduce the concentration of solid constituents in the mixture. The soobtained mixture with AEA was significantly less viscous and thus more workable and showed higher strength. As the early-age properties strongly influence the long-term performances, efforts have to be made to improve the behaviour of concrete at the fresh state. 
- As expected, the tested mixtures were less porous and more resistant to carbonation when water-cured than when aircured. However, the influence of curing was more noticeable for the mixtures with the lower clinker contents.

- In the case of air-curing, the porosities of all the mixtures were somewhat similar, although mix proportions and constituents were different. However, accelerated carbonation depths were quite different. As shown in our analysis, the result of accelerated carbonation test is not only governed by concrete microstructure but also by Portlandite content and water saturation degree.

- The concrete mixtures complying with the prescriptive requirements from EN 206-1 Standard showed significantly variable potential durability in terms of carbonation potential. The mixture designed with the presented method was found at least as resistant to accelerated carbonation as the mixture with blended cement complying prescriptive requirements of standard for exposure class XC3, used as a reference mixture. Based on the equivalent performance concept and the guidelines to apply this concept [20], it was concluded that the designed mixture is suitable to be used on construction site corresponding to the exposure classes XC1 and XC2.

Differences in carbonation resistance appeared to be much more important from accelerated tests than from tests in natural conditions. This questions the validity of the accelerated carbonation test defined in the French standard. As a consequence the design of accelerated carbonation tests to be used for performance-based specifications should include long-term monitoring of natural carbonation of concrete and the use of numerical models coupling hydration, drying and carbonation.

\section{Acknowledgements}

This study has been performed in the Project EcoBéton which is supported by the French National Research Agency (ANR - Agence Nationale pour la Recherche) under Grant Number ANR-06RGCU-006. The assistance of the Project partners is gratefully acknowledged.

\section{References}

[1] Parrott L. Cement, concrete and sustainability. A report on the progress of the UK cement and concrete industry towards sustainability. British Cement Association; 2002.

[2] Sjunnesson J. Life cycle assessment of concrete. Master thesis. Lund University; September 2005.

[3] SNBPE, Fiche de déclaration environnementale et sanitaire conforme à la norme NF P01-010. Poutre en béton armé XF1 C25/30 CEM II ; Septembre 2007 $<$ http://www.inies.fr> [in French].

[4] Gartner E. Industrially interesting approaches to "low- $\mathrm{CO}_{2}$ " cements. Cem Concr Res 2004;34(9):1489-98.
[5] Habert G, Roussel N. Study of two concrete mix-design strategies to reach carbon mitigation objectives. Cem Concr Compos 2009;31(6):397-402.

[6] Roskovic R, Bjegovic D. Role of mineral additions in reducing $\mathrm{CO}_{2}$ emission. Cem Concr Res 2005;35(5):974-8.

[7] Habert G, Billard C, Rossi P, Chen C, Roussel N. Cement production technology improvement compared to factor 4 objectives. Cem Concr Res 2010;40(5): $820-6$.

[8] Neville AM. Properties of concrete. New York: Wiley; 1996.

[9] European Standard EN 206-1. Concrete, specification, performance, production and conformity; 2004

[10] Rozière E, Loukili A, Cussigh F. A performance based approach for durability of concrete exposed to carbonation. Construct Build Mater 2009;23(1):190-9.

[11] Hooton RD, Mindess S, Roumain JC, Boyd AJ, Rear KB. Proportioning and testing concrete for durability. Concr Int ACI 2006;28(8):38-41.

[12] XP P18-458. Essai pour béton durci - Essai de carbonatation accélérée Mesure de l'épaisseur de béton carbonaté; 2008 [standard on accelerated carbontation test in French].

[13] Khokhar MIA, Rozière E, Turcry P, Grondin F, Loukili A. Mix design of concrete with high content of mineral additions: optimisation to improve early age strength. Cem Concr Compos 2010;32(5):377-85.

[14] De Larrard F. Concrete mixture proportioning - a scientific approach. Modern concrete technology series, no. 9, E\&FN SPON, Londres; 1999.

[15] De Larrard F, Sedran T. Mixture-proportioning of high-performance concrete. Cem Concr Res 2002;32(11):1699-704.

[16] Papadakis VG, Tsimas S. Supplementary cementing materials in concrete: Part I: efficiency and design. Cem Concr Res 2002;32(10):1525-32.

[17] Rajamane NP, Annie Peter J, Ambily PS. Prediction of compressive strength of concrete with fly ash as sand replacement material. Cem Concr Compos 2007;29(3):218-23.

[18] AFPC-AFREM. Durabilité des bétons, méthodes recommandées pour la mesure des grandeurs associées à la durabilité; 1997 [in French].

[19] Bolomey J. Determination of the compressive strength of mortars and concretes. Bull Tech Suisse Romande 1927;16 (22 and 24).

[20] Rozière E, Cussigh F. Méthodologie d'application du concept de performance équivalente des bétons, Recommandations professionnelles provisoires FNTP FFB CERIB, in French, Guidelines for the application of the equivalent performance concept. Report of the French concrete industry; 2009.

[21] Delmi MMY, Aït-Mokhtar A, Amiri O. Modelling the coupled evolution of hydration and porosity of cement-based materials. Construct Build Mater 2006;20(7):504-14.

[22] Bentz DP, Snyder KA, and Stutzman PE. Hydration of Portland cement: The effects of curing conditions. In: Justnes $\mathrm{H}$, editor. Proceedings of the 10 th international congress on the chemistry of cement, vol. 2.; $1997.8 \mathrm{pp}$.

[23] Baroghel-Bouny V, Nguyen TQ Dangla P. Assessment and prediction of RC structure service life by means of durability indicators and physical/chemical models. Cem Concr Compos 2009;31(8):522-34.

[24] Thiery M, Villain G, Dangla P, Platret G. Investigation of the carbonation fron shape on cementitious materials: effects of the chemical kinetics. Cem Concr Res 2007;37(7):1047-58.

[25] Papadakis VG. Effect of fly ash on Portland systems Part 1. Low-calcium fly ash Cem Concr Res 1999;29(11):1727-36.

[26] Mounanga P, Baroghel-Bouny V, Loukili A, Khelidj A. Predicting $\mathrm{Ca}(\mathrm{OH})_{2}$ content and chemical shrinkage of hydrating cement pastes using analytical approach. Cem Concr Res 2004;34(2):255-65.

[27] Snyder KA, Bentz DP. Suspended hydration and loss of freezable water in cement pastes exposed to $90 \%$ relative humidity. Cem Concr Res 2004;34(11):2045-56

[28] Papadakis VG. Effect of supplementary cementing materials on concrete resistance against carbonation and chloride ingress. Cem Concr Res 2000;30(2):291-9.

[29] Khokhar MIA, Rozière E, Grondin F, Loukili A Effect of mineral additives on some of durability parameters of concrete. In: Proceedings of international conference on advances in cement based materials and applications in civil infrastructure (ACBM-ACI) Lahore-Pakistan; December 12-14, 2007. p. 289300. 